\title{
Increased interaction of vascular endothelium and leucocytes after administration of antiplatelet serum: role in the developing vascular defect
}

\author{
IREN B. KOVACS ${ }^{1}$ AND J. P. CAEN \\ From the Laboratoire d'Immuno-Hématologie, Hôpital Lariboisière, 2, rue Ambroise Paré, 75475 Paris Cedex \\ 10, France
}

SUMMARY Antiplatelet serum (APS) induced an increase in the stickiness of white cells which manifests itself in the increase in number of granulocytes rolling along or sticking to the venous endothelium. Lidocaine treatment prevented the increased stickiness of white cells and, at the same time, the microvascular haemorrhage developing after APS. It can be assumed that increased stickiness of white cells after APS may contribute to endothelial damage.

Administration of antiplatelet sera (APS) is the most selective method to eliminate platelets from the circulation for the study of thrombocytopenic conditions. Although the specificity of APS was questioned by the early observation that such sera cross-reacted with a vascular endothelial antigen (Bedson, 1922; Elliott and Whipple, 1940), haemorrhagic vascular defects, which developed after the injection of APS, were attributed to severe thrombocytopenia (Kitchens and Weiss, 1975).

Administration of APS to rats causes a rapid and prolonged disappearance of circulating platelets. However, little consideration has previously been given to the transient leucocytopenia that also occurs after administration of APS and the possible role of granulocytes in the development of the ensuing microvascular lesions. During experiments on the microcirculation of rats treated with APS, a striking increase in the number of marginating (rolling) leucocytes was observed along the vascular wall immediately after the APS infusion. In the present study it is shown that administration of APS significantly increased the adhesive behaviour of leucocytes to venous endothelium. This transient effect may play a significant role in the vascular endothelial damage of small blood vessels that occurs in rats rendered thrombocytopenic by APS.

\section{Material and methods}

Antiserum to rat platelets was produced in rabbits.

1Present address: Korvin O. Hospital, 1071-Budapest, Hungary

Received for publication 7 June 1978
The serum used in the present study $(0.2 \mathrm{ml} / \mathrm{rat})$ regularly produced thrombocytopenia of about $10^{4}$ platelets per microlitre of blood. The antiserum agglutinated in vitro rat platelets but did not interreact with rat lymphocytes and granulocytes. Venous blood samples were taken from the cut rat tail. Total leucocyte counts were obtained by the haemocytometer method, and differential counts were made on 200 cells from the Giemsa-stained smears taken at the same time. Platelets were counted by phase microscopy (Brecher and Cronkite, 1950). Male rats (Sprague-Dawley, CFY strain, 150-180 g body weight) were anaesthetised with pentobarbital sodium $(60 \mathrm{mg} / \mathrm{kg}$ subcutaneously supplemented with $5 \mathrm{mg} / \mathrm{kg}$ intramuscularly at 30-minute intervals).

Mesoappendix microcirculation was prepared according to Zweifach (1965). Microvasculature was observed through a long-distance focusing objective (UM-20, Leitz) and the microscopic field was enlarged electronically (up to $\times 6000$ ) by a television camera and monitor system. The diameter of the vessels was determined by the calibrated scale of the monitor screen. The microscope was focused sharply on the edge of the blood vessel. Long, straight venules, the diameter ranging between 40 and $55 \mu \mathrm{m}$, were selected. The number of 'rolling' and 'sticking' leucocytes was recorded. A granulocyte was considered to be rolling if it was seen moving slowly along the endothelium at a rate less than that of the axial stream of the venule. A granulocyte was considered to be sticking if it was firmly adherent to the endothelial surface or if it stopped rolling for more than 30 seconds during the observation period.

As the handling and the exteriorisation of the mesentery caused an initial increase in the number of 
adhesive granulocytes (Atherton and Born, 1972), a 15-minute resting period was necessary for stable blood flow with a small number of adhesive leucocytes. Observations were therefore always started after this resting period. Two types of observation were made:

1 From the microscopic field a $500 \mu \mathrm{m}$ length of vessel was selected by a shield on the monitor-screen. A line perpendicular to the axis of the vessel was drawn on the screen in the middle of this section. Rolling cells were counted for 1 minute on both sides of the vessel beyond this line. Sticking leucocytes were counted during the 1-minute observation time along both sides of the selected vessel-length (sticking I).

2 A long venule (diameter of vessel $30-70 \mu \mathrm{m}$ ) was selected for observation. The microscopic field on the screen covered an $800 \mu \mathrm{m}$ length of the vessel. Five microscopic fields $(4000 \mu \mathrm{m})$ of the straight sections of the venule were analysed by counting sticking leucocytes along both sides of the vessel wall, and these data were expressed as the total sum of sticking cells per $4000 \mu \mathrm{m}$ vessel-length (sticking II).

Under normal conditions haemorrhagic lesions were never observed in the mesoappendix microvasculature. An attempt was made to quantify the

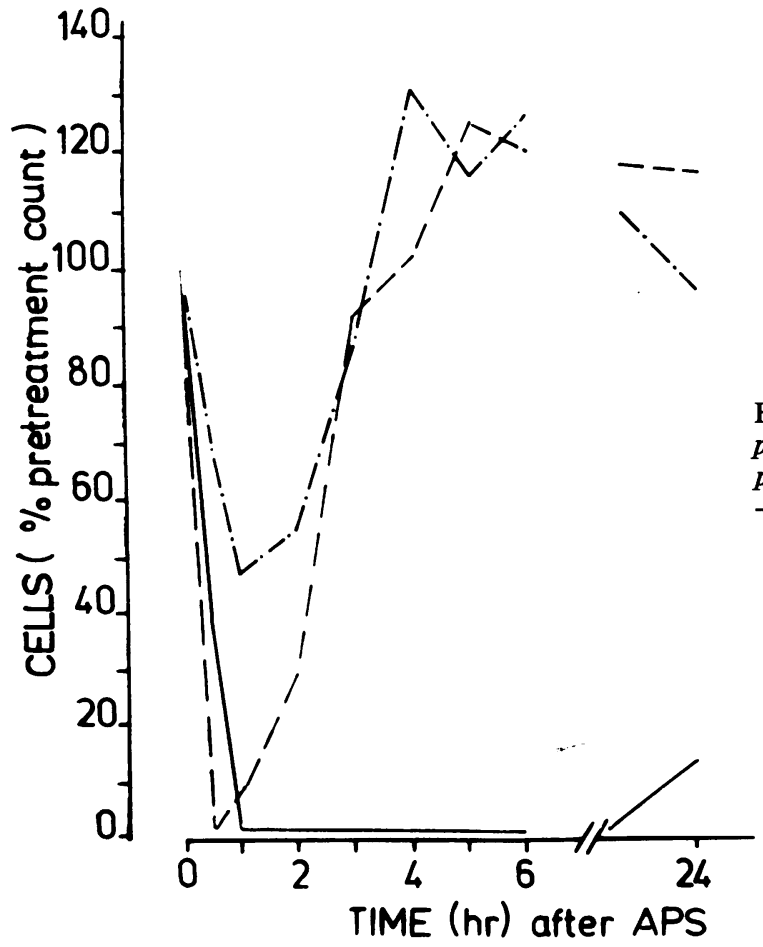

vascular defect developing regularly after $0.2 \mathrm{ml}$ APS by counting haemorrhagic lesions using a low-power objective along the whole mesoappendix preparation 2 hours after the administration of APS.

Lidocaine $\mathrm{HCl}$, when employed, was administered intravenously as a slow infusion via the tail vein by a peristaltic pump at $1.2 \mathrm{ml} / \mathrm{h}$. The infusion was started just after APS had been administered.

\section{Results}

The effect of APS on platelet, total white blood cell, and granulocyte counts is shown in Figure 1. While rats remained severely thrombocytopenic for the duration of the experiment ( 24 hours), granulocyte and leucocyte counts returned to the preinjection level within 3 hours, followed by a moderate leucocytosis and granulocytosis.

Soon after the administration of APS, adhesive granulocyte counts increased significantly (Table 1). Anti-rat plasma rabbit serum or non-immune rabbit serum did not influence rolling and sticking leucocyte counts (results not shown).

While the number of marginating cells decreased with time, the number of sticking white cells remained increased for hours. Lidocaine treatment prevented a drop of granulocyte counts and subsequent

Fig. 1 Effect of $0 \cdot 2$ ml antiplatelet serum (APS) on platelets, total white cells, and granulocyte counts of peripheral blood. Mean values obtained in six rats: platelets; - - total WBC; -1 granulocytes. 
Table 1 Influence of antiplatelet serum on granulocyte margination and adherence phenomena

\begin{tabular}{llll}
\hline $\begin{array}{l}\text { Minutes } \\
\text { after } A P S \\
(0 \cdot 2 \mathrm{ml})\end{array}$ & $\begin{array}{l}\text { No. of } \\
\text { rats }\end{array}$ & \multicolumn{2}{l}{ No. of granulocytes (mean) } \\
\cline { 2 - 4 } \cline { 3 - 3 } & & Rolling & Sticking I \\
\hline 15 & 18 & 5 & $1 \cdot 2$ \\
30 & 12 & $27^{*}$ & $6 \cdot 7^{*}$ \\
45 & 12 & $53^{*}$ & $5 \cdot 4^{*}$ \\
60 & 12 & $38^{*}$ & $8 \cdot 2^{*}$ \\
120 & 11 & 11 & $11 \cdot 6^{*}$ \\
180 & 9 & 13 & $13 \cdot 4^{*}$ \\
& 7 & 7 & $8 \cdot 5^{*}$ \\
\hline
\end{tabular}

For the meaning of 'rolling' and 'sticking', see Methods.

Difference from the values measured before administration of APS-0 min. $\quad * \mathbf{P}<0.001 \quad$ tP $<0.01$

elevation of white cell stickiness in response to APS (Table 2). A typical microvascular haemorrhage, seen frequently after APS, is shown in Figure 2. Lidocaine treatment prevented $(P<0.001)$ these vascular defects and subsequent purpura formation in APS-injected rats.

\section{Discussion}

Thrombocytopenia produced by injection of antiplatelet serum into experimental animals has been widely used to study thrombocytopenic conditions and the role of platelets in various pathological reactions. Other techniques used to make animals thrombocytopenic, such as whole-body irradiation or cytotoxic drugs (Busulfan), induce concomitant severe granulocytopenia. APS also causes reduction of white cell counts with a more severe drop of granulocyte counts, but these counts returned to the preinjection level at 4-6 hours, while the platelet count was still diminished. Platelet antiserum, therefore, allows the desired effect of producing selective thrombocytopenia without leucopenia if the animal is studied a few hours after the administration of the serum.

According to our present findings, a shift of leucocytes (mainly granulocytes) from the circulating to the marginated pool appears to be responsible for the drop in peripheral leucocyte counts after APS. The observed increase in the number of marginating and sticking leucocytes indicates an increased endothelial leucocyte interaction.

The adherence of white blood cells to the endothelium of blood vessels is the first step in the leucocyte emigration process and is therefore of great pathological significance (Grant, 1973). Experimental evidence indicates that in the venules, white cell endothelial adherence and emigration per se produce endothelial damage by releasing leucocyte cytotoxic substances (Stewart et al., 1974 and 1977). These foci of vessel wall damage may well serve as a point for red cells to permeate the walls of small vessels during severe thrombocytopenia.

There are two possible causes of the increased leucocyte-endothelium interaction observed after APS:

(a) Sticking of white cells to the vessel wall has been attributed to changes in the endothelium itself (Grant, 1973). The effect of APS can thus be explained by direct damage to endothelial cells (McDonald and Clift, 1976), which makes them sticky for white cells.

(b) Recent evidence indicates that the primary changes may be located in or on the granulocytes themselves (Fehr and Jacob, 1977). It has been shown that granulocyte margination and adherence are complement-dependent functions. APS-induced abrupt granulocytopenia may be the result of complement activation resulting from the aggregation and lysis of platelets (Wautier et al., 1976) after antibody/ platelet interaction, or may reflect a direct APS/ granulocyte interaction.

In his classical experiments, Bedson (1922) first showed the simultaneous need for both thrombocytopenia and small vessel damage in the production of purpura. As in the case of APS, purpura occurred without the need for additional damage to the

Table 2 Effect of lidocaine on antiplatelet, serum-induced, increased granulocyte adherence and vascular defect

\begin{tabular}{|c|c|c|c|c|c|c|c|c|}
\hline \multirow{2}{*}{$\begin{array}{l}\text { Minutes } \\
\text { after } \\
\text { APS } \\
(0.2 \mathrm{ml})\end{array}$} & \multicolumn{4}{|l|}{ Controls } & \multicolumn{4}{|c|}{ Lidocaine-treated rats $\dagger$} \\
\hline & No. of rats & $\begin{array}{l}\text { Sticking } \\
\text { count II }\end{array}$ & $\begin{array}{l}\text { No. of } \\
\text { purpuric } \\
\text { lesions }\end{array}$ & $\begin{array}{l}\text { Granulocytes } \\
\left(\times 10^{3} \mathrm{~mm}^{-3}\right)\end{array}$ & No. of rats & $\begin{array}{l}\text { Sticking } \\
\text { count II }\end{array}$ & $\begin{array}{l}\text { No. of } \\
\text { purpuric } \\
\text { lesions }\end{array}$ & $\begin{array}{l}\text { Granulocytes } \\
\left(\times 10^{3} \mathrm{~mm}^{-3}\right)\end{array}$ \\
\hline $\begin{array}{r}0 \\
15 \\
30 \\
45 \\
60 \\
120\end{array}$ & $\begin{array}{r}18 \\
12 \\
12 \\
12 \\
11 \\
9\end{array}$ & $\begin{array}{r}4 \\
23 \\
86 \\
52 \\
34 \\
27\end{array}$ & $8 \cdot 6$ & $0 \cdot 24$ & $\begin{array}{l}8 \\
8 \\
8 \\
8 \\
8 \\
7\end{array}$ & $\begin{array}{l}2 \\
6^{*} \\
5^{*} \\
8^{*} \\
7^{*} \\
4^{*}\end{array}$ & $0.8^{*}$ & $1 \cdot 43 *$ \\
\hline
\end{tabular}

* $P<0.001$ from the respective controls

$+0.1 \mathrm{mg} / \mathrm{min}$ for $60 \mathrm{~min}$, started immediately after the administration of APS (total dose $=40 \mathrm{mg} / \mathrm{kg} / \mathrm{h}$ ) 

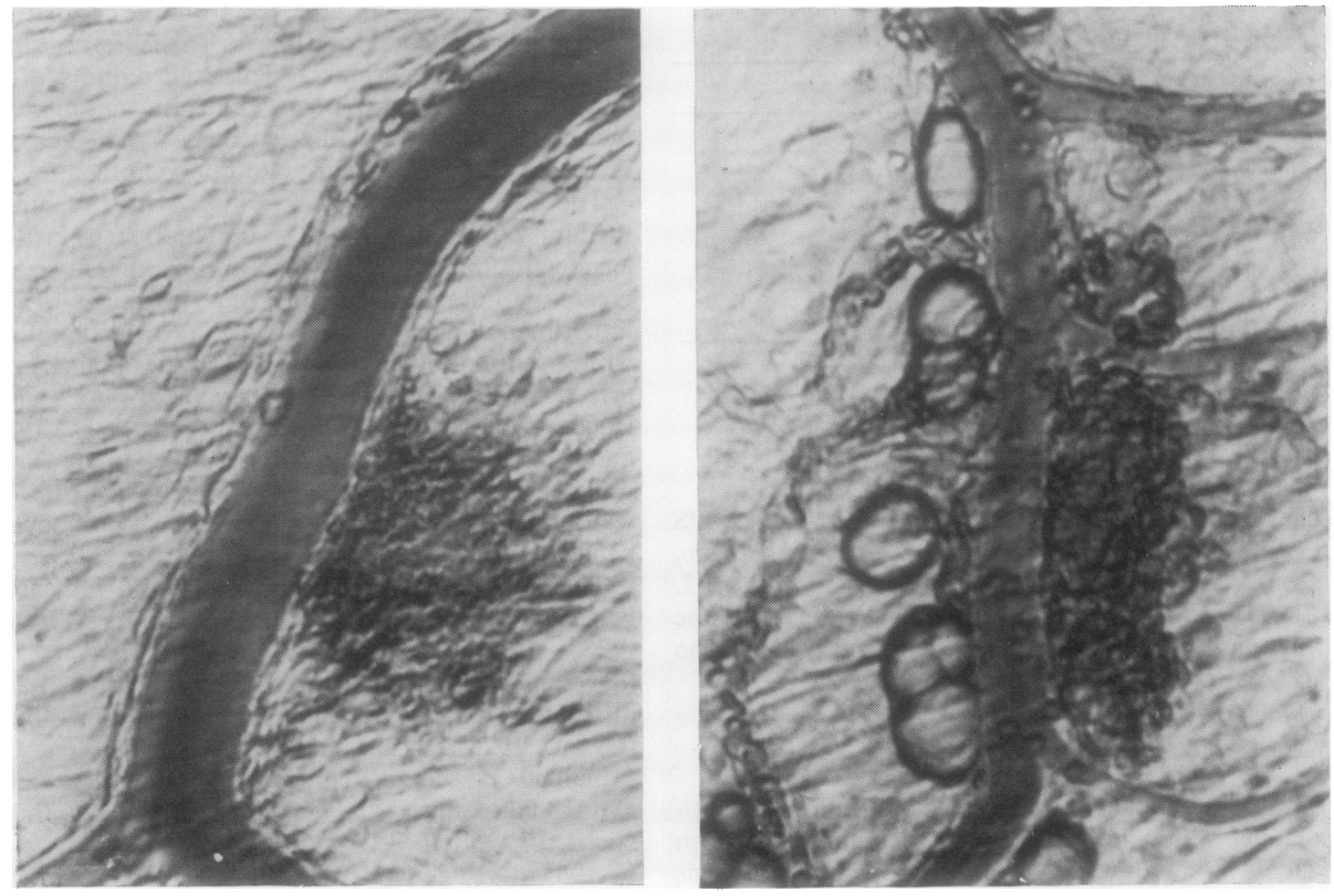

Fig. 2 Typical microvascular defect seen frequently in the mesentery of the antiplatelet serum injected rat $0 \cdot 2 \mathrm{ml} / \mathrm{rat} / 2$ hours after the administration of serum. Increased numbers of granulocytes sticking to the endothelium have always been observed at the site where haemorrhage is developing.

endothelium. APS was considered to be causing direct vascular damage (Ackroyd, 1953) by a hypothetical cross-reaction of antiplatelet antibodies with blood vessel endothelial antigens (Ubatuba et al., 1975).

To study the role of the increased stickiness of white cells after APS in producing endothelial damage, lidocaine was administered to rats. Lidocaine, like other cationic local anaesthetics, has been reported to influence cellular responses to surface stimuli by interfering with the function of microtubules and microfilaments. Electron microscopic examination of drug-treated cells has shown that microtubules and microfilaments appear normal in 'resting' polymorphonuclear leucocytes, but the increase in microtubules normally observed in stimulated cells was not seen after treatment (Goldstein et al., 1977). Lidocaine inhibited white cell sticking in vivo (Giddon and Lindhe, 1972) and prevented the endothelial damaging effect of white cells (Stewart et al., 1974). Our present finding that lidocaine inhibited APS-induced sticking of white cells and simultaneously prevented vascular defects without influencing thrombocytopenia makes it 3 highly probable that the two phenomena are causally related.

From the present study the following conclusions can be reached: APS-induced increased stickiness of white cells contributes to or plays a decisive role in the endothelial damage developing later in this condition. Although peripheral white cell counts $N$ are restored within a few hours, mainly by cells $N$ coming from the bone marrow reserve pool, the N vascular wall damage effect is long-lasting. For this ${ }_{\sigma}^{\omega}$ reason, the presence of a pathological reaction (eg, inflammation) during APS-induced severe thrombocytopenia does not necessarily mean that platelets are not involved in this process (Giddon and Lindhe, 1972). In addition to primary haemostatic functions, platelets are assumed to be involved $\vec{D}$ as inflammatory cells in the pathogenesis of some $\frac{\sim}{\mathbb{Q}}$ diseases (Nachman, 1973), increasing the permeability of endothelium during cellular passage.

As such inflammatory endothelial changes are 
found after APS with relatively few platelets in the circulation, the importance of platelets in initiating endothelial damage cannot be studied properly under APS-induced thrombocytopenic conditions.

One of us (IBK) was in receipt of a post-doctoral fellowship. Support from the Fondation pour la Recherche Médicale, France, during the final stages is gratefully acknowledged. The help of W. Nicholls in preparing the manuscript is acknowledged.

\section{References}

Ackroyd, J. F. (1953). Allergic purpura including purpura due to foods, drugs and infections. American Journal of Medicine, 14, 605-632.

Atherton, A., and Born, G.V.R. (1972). Quantitative investigations of the adhesiveness of circulating polymorphonuclear leucocytes to blood vessel walls. Journal of Physiology, 222, 447-474.

Bedson, S. P. (1922). Blood-platelet antiserum, its specificity and role in the experimental production of purpura. Journal of Pathology and Bacteriology, 25, 94-104.

Brecher, G., and Cronkite, E. P. (1950). Morphology and enumeration of human blood platelets. Journal of Applied Physiology, 3, 365-377.

Elliott, R. H. E., and Whipple, M. A. (1940). Observations on the inter-relationship of capillary, platelet, and splenic factors in thrombocytopenic purpura. Journal of Laboratory and Clinical Medicine, 26, 489-498.

Fehr, J., and Jacob, H. S. (1977). In vitro granulocyte adherence and in vivo margination: two associated complement-dependent functions. Studies based on the acute neutropenia of filtration leukophoresis. Journal of Experimental Medicine, 146, 641-652.

Giddon, D. B., and Lindhe, J. (1972). In vivo quantitation of local anesthetic suppression of leukocyte adherence. American Journal of Pathology, 68, 327-338.

Goldstein, I. M., Lind, S., Hoffstein, S., and Weissmann, G. (1977). Influence of local anesthetics upon human polymorphonuclear leukocyte function in vitro.
Reduction of lysosomal enzyme release and superoxide anion production. Journal of Experimental Medicine, 146, 483-494.

Grant, L. (1973). The sticking and emigration of white blood cells in inflammation. In The Inflammatory Process, edited by B. W. Zweifach, L. Grant, and R. T. McCluskey, Chapter 7, pp. 205-249. 2nd ed. Academic Press, New York.

Kitchens, C. S., and Weiss, L. (1975). Ultrastructural changes of endothelium associated with thrombocytopenia. Blood, 46, 567-578.

McDonald, T. P., and Clift, R. (1976). Mechanism of thrombocytopenia induced in mice by anti-platelet serum. Haemostasis, 5, 38-50.

Nachman, R. L. (1973). The platelet as an inflammatory cell. In Cerebral Vascular Diseases: Eighth Conference, edíted by F. H. McDowell and R. W. Brennan. Grune and Stratton, New York.

Stewart, G. J., Lynch, P. R., Reichle, F. A., Ritchie, W. G. M., Smith, A., and Schaub, R. G. (1977). The adhesion of leukocytes, erythrocytes, and noncellular material to the luminal surface of natural and artificial blood vessels in vivo. Annals of the New York Academy of Sciences, 283, 179-207.

Stewart, G. J., Ritchie, W. G. M., and Lynch, P. R. (1974). Venous endothelial damage produced by massive sticking and emigration of leukocytes. American Journal of Pathology, 74, 507-521.

Ubatuba, F. B., Harvey, E. A., and Ferreira, S. H. (1975). Are platelets important in inflammation? Agents and Actions, 5, 31-34.

Wautier, J. L., Souchon, H., Cohen-Solal, L., Peltier, A. P., and Caen, J. P. (1976). $C_{1}$ and human platelets. III. Role of $C_{1}$ subcomponents in platelet aggregation. induced by aggregated IgG. Immunology, 31, 595-599.

Zweifach, B. W. (1965). Current concepts of micro' circulatory behavior. Bibliotheca Anatomica, 7, 2-8.

Requests for reprints to: Professor J. P. Caen, Hôpital Lariboisière, Laboratoire d'Immuno-Hématologie, 2 rue A. Paré, 75475 Paris Cedex 10, France. 